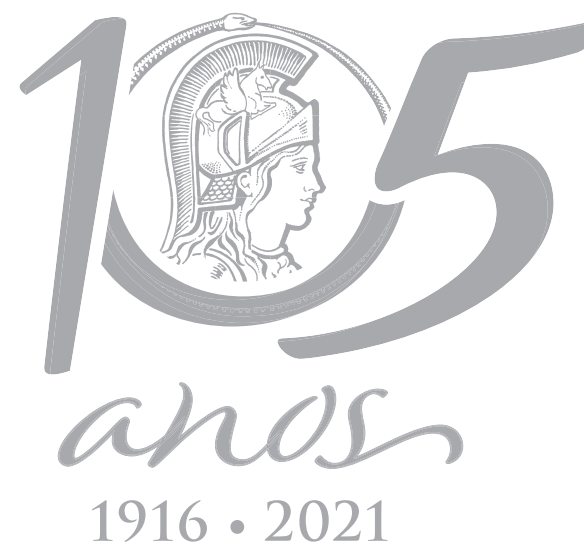

\title{
Green coffee extract attenuates Parkinson's- related behaviors in animal models
}

\author{
GRAZIELLA R. MOLSKA, LYVIA IZAURA G. PAULA-FREIRE, MARNA E. SAKALEM, \\ DANIELE O. KÖHN, GIUSEPPINA NEGRI, ELISALDO A. CARLINI \& FÚLVIO R. \\ MENDES
}

\begin{abstract}
Epidemiological studies have shown an inverse association between coffee consumption and the development of Parkinson's disease (PD). The effects of the oral treatment with green (non-roasted) coffee extracts (CE, 100 or $400 \mathrm{mg} / \mathrm{kg}$ ) and caffeine $(31.2 \mathrm{mg} / \mathrm{kg}$ ) were evaluated on catalepsy induced by haloperidol in mice, and unilateral 6-OHDA lesion of medial forebrain bundle (MFB) or striatum in rats. Also, the in vitro antioxidant activity and the monoamine levels in the striatum were investigated. CE presented a mild antioxidant activity in vitro and its administration decreased the catalepsy index. CE at the dose of $400 \mathrm{mg} / \mathrm{kg}$ induced ipsilateral rotations 14 days after lesion; however, chronic 30-day CE and caffeine treatments did not interfere with the animals' rotation after apomorphine or methamphetamine challenges in animals with MFB lesion, nor on monoamines levels. Furthermore, CE and caffeine were effective in inhibiting the asymmetry between ipsilateral and contralateral rotations induced by methamphetamine and apomorphine in animals with lesion in the striatum but did not avoid the monoamines depletion. These results indicate that CE components indirectly modulate dopaminergic transmission, suggesting a pro-dopaminergic action of $\mathrm{CE}$, and further investigation must be conducted to elucidate the mechanisms of action and the possible neuroprotective role in PD.
\end{abstract}

Key words: Coffea arabica, Parkinson's disease, catalepsy, chlorogenic acids, caffeine, neuroprotection.

\section{INTRODUCTION}

Parkinson's disease (PD) is considered the second most common neurodegenerative disorder, with an estimated prevalence of 1 to $3 \%$ in the population over the age of 65 years, and with an increasing prevalence among older people (Del Rey et al. 2018). PD is mainly characterized as a progressive degeneration of dopaminergic neurons in substantia nigra parscompacta, and the presence of Lewy bodies (intraneuronal aggregates of $\alpha$-synuclein and other misfolded proteins) is one of the most important neuropathological hallmarks (Maiti et al. 2017). Although the pathophysiology of PD is complex, oxidative stress is thought to play an important role in dopaminergic neurotoxicity (Blesa et al. 2015). The increased dopamine oxidation associated with decreased endogenous antioxidant defense are key elements in the development of the disease (Maiti et al. 2017).

The current medicines used in PD are able to improve the quality of life, but cannot avoid the progressive neuron degeneration, making it important to identify potential protective factors such as diet or life style that could diminish the risk of developing PD, and also, to find new drugs 
which could avoid the disease progression. Several observational studies and meta-analysis have shown an inverse correlation between coffee consumption and incidence of PD, what leads to the hypothesis that caffeine presents a protective effect on PD (Hu et al. 2007, Qi \& Li 2014, Ross et al. 2000, Sääksjärvi et al. 2008).

Coffee is one of the most consumed beverages worldwide, being usually prepared by the infusion of roasted and grounded seeds of Coffea arabica L. or its varieties (van Dam et al. 2020). The psychological effects of coffee are largely due to the presence of caffeine, which acts mainly through the adenosine receptors antagonism, more specifically as antagonist of adenosine $A_{1}$ and $A_{2 A}$ receptors (Tóth et al. 2019). The adenosinergic system is co-localized with dopaminergic neurons in several brain regions, in special in the basal ganglia, where it negatively modulates the dopaminergic system (Chen \& Chern 2011, Tóth et al. 2019). The blockage of adenosine $A_{2 A}$ receptors on striatal neurons has been suggested to explain the neuroprotective action of caffeine in PD (BataGarcía et al. 2007, Chen \& Chern 2011, Kalda et al. 2006, Kelsey et al. 2009). Recently, tradefylline, a selective adenosine $A_{2 A}$ receptor antagonist, was approved by FDA as an add-on treatment of PD patients under treatment with levodopa presenting off episodes (Chen \& Cunha 2020).

Nevertheless, although the neuroprotective effect of coffee on PD is attributed mainly to caffeine, several authors emphasize the importance of polyphenols and other constituents, suggesting that they can strongly contribute to the beneficial effects of coffee, tea and other caffeinated beverages (Heitman \& Ingram 2017, Zhou et al. 2019, Socała et al. 2020). It has been previously demonstrated that the amount of chlorogenic acids and its derivatives, caffeic acid, ferulic acid, quinic acid and several flavonoids, depends on the variety of coffee, roasting process and methods of preparation (Priftis et al. 2015, Wolska et al. 2017). Depending on the temperature and roasting time, most chlorogenic acids and other constituents are changed or decomposed, while caffeine remains almost unaffected (Hečimović et al. 2011, Priftis et al. 2015). Then, the complex mixture of bioactive compounds present in coffee beans is responsible for its multidirectional effects on the human health (Socała et al. 2020).

chlorogenic acids (quinic esters of hydroxycinnamic acids) is a family of esters formed between quinic acid and three most common trans-cinnamic acids: caffeic acid, ferulic acid and p-coumaric acid. The main chlorogenic acids classes in green coffee are: caffeoylquinic acids, dicaffeoylquinic acids, and feruloylquinic acids (Monteiro \& Farah 2012). The potential neuroprotective effects of chlorogenic acid have been shown in several in vitro and in vivo studies (Nabavi et al. 2016). Currently, there is evidence of the protective role of chlorogenic acids and its derivatives in PD and Alzheimer's disease, based on both epidemiological and experimental studies (Cropley et al. 2012, Heitman \& Ingram 2017, Taram et al. 2016, Zhou et al. 2019). Recent studies have demonstrated the neuroprotective effect of chlorogenic acids in experimental models of PD using different neurotoxins (Singh et al. 2018, Miyazaki et al. 2019, Shan et al. 2019). It is suggested that chlorogenic acids and their metabolites confer neuroprotective effects against oxidative stress and promote neuronal differentiation, in addition to improving attention and executive function in patients with mild cognitive impairment (Tajik et al. 2017, Ochiai et al. 2019).

Due to the neuronal loss, in particular in the basal nuclei, PD presents various motorrelated disturbances, such as bradykinesia, resting tremor, rigidity, and postural instability (Del Rey et al. 2018). As a result, most animal 
models of PD have focused on motor deficits. Catalepsy induced by haloperidol has been used as a pharmacological model to study pro- and anti-dopaminergic drugs and it is very useful as a screening test. Unilateral lesion in the nigrostriatal dopaminergic pathway induced by neurotoxins has been used as an animal model to mimic the neuronal loss typical to PD (Björklund \& Dunnett 2019). The unilateral lesion induces an impaired use of contralateral forelimb, which is best evaluated after challenge with dopaminergic agonists.

The aim of the present study was to investigate the effects of caffeine and green (non-roasted) coffee extract on PD-related behavioral alterations in experimental models. We analyzed the chemical composition and caffeine content of a coffee extract rich in chlorogenic acids and evaluated the effect of the oral administration on the catalepsy induced by haloperidol model, and in the rotational behavior model after unilateral 6-OHDA lesion of medial forebrain bundle or striatum.

\section{MATERIALS AND METHODS}

\section{Coffee extract}

Green coffee extract (CE) produced by spray dryer technique with dry unroasted seeds of coffee (Coffea arabica $\mathrm{L}$ ) was acquired from Centroflora (Botucatu, Brazil). The extract was evaluated for its physical and chemical characteristics by IT2 100 method (standardized in 21.04\% of chlorogenic acid, $27-33 \%$ of caffeoylquinic acid and $7.5 \%$ to $8 \%$ of caffeine), according to the report provided by the manufacturer.

\section{Drugs}

Apomorphine, caffeine and 6-hydroxydopamine (6-OHDA) were purchased from Sigma (St. Louis, USA) and haloperidol (Haldol ${ }^{\oplus}$ ) from Janssen Pharmaceutica N.V. (Beerse, Belgium).
Methamphetamine was donated by the Brazilian Federal Police. For HPLC analysis, caffeine standard was purchased from Fluka (Munich, Germany) and 5-O-caffeoylquinic acid standard from Sigma-Aldrich (Milano, Italy). HPLC-grade methanol was purchased from Merck (Darmstadt, Germany) and HPLC-grade water was prepared from distilled water using a Milli-Q system (Millipore, Waters, Milford, USA).

\section{Phytochemical analysis and caffeine dosage}

Caffeine quantification in CE was carried out through phase reversed high-performance liquid chromatography with Diodo Array detector (HPLC/DAD). The HPLC-DAD analyses were conducted on a Hewlett Packard 1090 II equipped with a degasser, an autosampler, and diode array detector. The identification of caffeine was based on retention time, UV spectra comparison with a standard and spiking. Quantitation was obtained through a calibration curve made with known concentrations of caffeine. The calibration curve for caffeine $(Y=$ 2935.6 X) was found to be linear with $R^{2}=0.99$.

The coffee extract was dissolved in water: methanol $(80: 20) \mathrm{v} / \mathrm{v}(5 \mathrm{mg} / 2 \mathrm{~mL})$ and filtered with a $0.45 \mu \mathrm{m}$ polytetrafluoroethylene (PTFE) filter, prior to injection of $31.2 \mu \mathrm{L}$ into the HPLC system, using a reverse phase, C18, Spherisorb ODS II (Hewlett Packard) column (4.6 × 250 mm, $5 \mu \mathrm{m})$, connected to a guard column. Spectral UV data from all peaks were collected in the spectral range 240 - $400 \mathrm{~nm}$, and chromatograms were recorded at 330 (caffeoylquinic acid derivatives and feruloylquinic acids derivatives) and $270 \mathrm{~nm}$ (caffeine) (Navarra et al. 2017). The mobile phases consisted of eluent A ( $0.1 \%$ aq. formic acid) and eluent $B$ (methanol), with the following gradient profile: 0 min $-20 \% \mathrm{~B}$ in $A ; 10 \min -30 \% B$ in $A, 20$ min $-50 \%$ B in $A ; 30$ min $-70 \%$ B in $A ; 40$ min- $90 \%$ B in $A ; 45$ min $-40 \% B$ in $A$ and finally returned to the initial conditions (20\% $B$ in $A$ ) 
to re-equilibrate the column prior to another run. The flow rate was kept constant at $0.8 \mathrm{~mL} /$ min, and the temperature of the column was maintained at $28^{\circ} \mathrm{C}$.

\section{Animals}

Male Swiss mice (40 to $50 \mathrm{~g}$ ) and male Wistar rats (300 to $400 \mathrm{~g}$ ) 2-5 months old were provided by the bioterium of Psychobiology from Universidade Federal de São Paulo (UNIFESP). Animals were kept in rooms with controlled temperature $\left(23 \pm 2^{\circ} \mathrm{C}\right)$ and light/dark cycle of 12 hours with water and food ad libitum. The project was approved by the Ethics Committee of UNIFESP (CEP \#1946/06) and we followed the ARRIVE guidelines principles of the use of laboratory animals.

\section{Animals' treatment}

CE (doses of 100 and $400 \mathrm{mg} / \mathrm{kg}$ ) and caffeine (31.2 $\mathrm{mg} / \mathrm{kg}$ - the equivalent caffeine in $400 \mathrm{mg} /$ $\mathrm{kg}$ of $\mathrm{CE}$ ) were solubilized in water and orally (po) administered by gavage in the volume of $1 \mathrm{~mL} / \mathrm{kg}$ (rats) and $10 \mathrm{~mL} / \mathrm{kg}$ (mice). The control animals received the vehicle water at the same volume by gavage. The doses were chosen based in a pilot study (screening) which showed that these doses did not cause significant behavioral alterations in the animals. According to van Dam et al. (2020) the average daily dose of caffeine consumed by US Americans is $135 \mathrm{mg}$ (which results at around $1.93 \mathrm{mg} / \mathrm{kg}$ of caffeine for an adult of $70 \mathrm{Kg}$ ) corresponding to 1.5 cups of coffee. It is important to keep in mind that rodents present a higher metabolism rate, what demands the use of higher doses in comparison to human studies.

\section{Evaluation of antioxidant capacity in vitro}

Antioxidant activity was evaluated by the lipid peroxidation inhibition assay, which was measured by malondialdehyde concentration in rat brain homogenate. Tissue homogenate was prepared with phosphate buffer and centrifuged at 3000 rpm for 15 minutes. The supernatant was collected and then diluted again in phosphate buffer (1:3). Five concentrations of CE (0.25, $0.5,0.75,1$ and $2 \mathrm{mg} / \mathrm{mL}$ ) were added to each homogenate tube and then incubated in water bath with thiobarbituric acid for 60 minutes at $37^{\circ} \mathrm{C}$ at final concentrations of $4.17,8.33,12.50,16.67$ and $33.33 \mu \mathrm{g} / \mathrm{mL}$. The experiment was carried out according to the methodology described by Stocks et al. (1974). The antioxidant activity in vitro was determined for each concentration of the extract and the concentration inhibiting $50 \%$ of lipid peroxidation $\left(\mathrm{Q}_{1 / 2}\right)$ was calculated by linear regression using the log of the concentration and the percentage of inhibition (mean of 4 assays).

\section{Experiment 1: Catalepsy induced by haloperidol}

Haloperidol-induced catalepsy has been used as animal models of PD and to study the effect of drugs on dopaminergic system (Trevitt et al. 2009). Groups of 10-13 mice received CE (100 or $400 \mathrm{mg} / \mathrm{kg}$; experimental groups), saline, or caffeine (31.2 mg/ kg; positive control) by gavage (via oral), either acutely or for 15 consecutive days (except caffeine group). Thirty minutes after the acute or the last administration of each treatment, the animals received haloperidol (5 mg/ kg, intraperitoneally - ip), except for the negative control group, which received saline (ip).

Forty-five minutes after the administration of haloperidol (or saline) the animals were placed with their forepaws positioned on a bar suspended $5 \mathrm{~cm}$ above the bench and the catalepsy time (immobility) was recorded (Rodrigues et al. 2008). The number of times each animal successfully pulled out of the bar was recorded for 10 minutes, with a limit of 10 
times. The catalepsy index was calculated by the rate between the total catalepsy time and the number of times the mice left the bar.

\section{Unilateral lesion induced by 6-OHDA}

Unilateral lesion in the nigrostriatal dopaminergic pathway induced by 6-OHDA induces an asymmetry in motor performance, easily recognized in animals by asymmetric body posture and impaired use of contralateral forelimb through the apomorphine/ amphetamine rotation test (Björklund \& Dunnett 2019). We induced unilateral lesion in two distinct sites of nigrostriatal pathway, as described in "surgical procedure".

\section{Surgical procedure}

Male Wistar rats were anesthetized with ketamine (90 mg/ kg, ip) and xylazine $(5 \mathrm{mg} / \mathrm{kg}$, ip) and placed on a stereotaxic apparatus. After the skin incision and the skull exposition, a hole was performed to the bone using a dentist drill and the neurotoxin 6-OHDA ( $12 \mu \mathrm{g} / 2 \mu \mathrm{L}$ buffered saline in $0.2 \%$ ascorbic acid) was infused with an injection pump (Da Cunha et al. 2008) in the medial forebrain bundle (MFB) of the right hemisphere (experiment 2) or in the right striatum (experiment 3) in the lesioned group, while sham-operated animals were infused with $2 \mu \mathrm{L}$ of buffered saline. The coordinates for MFB lesion were: AP, -1.9 mm; ML, -1.9 mm; DV, -7.2 mm of bregma; and for striatum: AP, +0.5 mm; ML, -2.5 mm; DV $-4.5 \mathrm{~mm}$; according to the brain atlas Paxinos \& Watson (2004). After surgery, dental wax was applied on the skull to close the access hole, the head skin was sutured, and the animals were allowed to recover in individual boxes with food, water, and controlled temperature. The experimental design of experiments 2 and 3 is shown on Figure 1. A pilot study showed that the lesion was effective in inducing neuronal loss in the substantia nigra (Figure 1 - qualitative analysis).

\section{Experiment 2: Unilateral lesion on MFB}

\section{Experiment 2A. Effect of the acute treatment with $C E$, apomorphine and methamphetamine on the rotational behavior of rats}

Groups of 10-15 rats lesioned on MFB with 6-OHDA were challenged acutely on the $14^{\text {th }}$ day with CE (100 or $400 \mathrm{mg} / \mathrm{kg}$ ), caffeine (31.2 mg/ $\mathrm{kg}$ ) or vehicle by gavage. An extra group of rats that received buffered saline instead of 6-OHDA (sham-operated group) was challenged with CE $(400 \mathrm{mg} / \mathrm{kg})$ on the $14^{\text {th }}$ day. Immediately after the respective treatments, the animals were evaluated for 60 minutes and the number of contralateral and ipsilateral complete rotations $\left(360^{\circ}\right)$ in a cylinder was recorded (Ungerstedt \& Arbuthnott 1970). On the $15^{\text {th }}$ day, all animals received apomorphine $(0.1 \mathrm{mg} /$ $\mathrm{kg}$, subcutaneously - sc), and on the $16^{\text {th }}$ day, methamphetamine $(2.5 \mathrm{mg} / \mathrm{kg}$, ip), and the number of ipsilateral and contralateral rotations was recorded again. There was no treatment with CE or caffeine on days 15 and 16.

\section{Experiment 2B: Effect of repeated treatment with CE on the rotational behavior of rats challenged with apomorphine and methamphetamine}

For this experiment, groups of 12-15 rats lesioned on MFB were orally treated for 30 days with CE (100 or $400 \mathrm{mg} / \mathrm{kg}$ ), caffeine (31.2 mg/ $\mathrm{kg}$ ) or vehicle, by gavage. An extra group of sham-operated rats received vehicle by gavage for the same period. On the $15^{\text {th }}$ and $29^{\text {th }}$ days after surgery the animals were evaluated for 60 minutes regarding the number of ipsilateral or contralateral rotations, after administration of apomorphine $(0.1 \mathrm{mg} / \mathrm{kg}, \mathrm{sc})$. On $16^{\text {th }}$ and $30^{\text {th }}$ 


\section{Experiment 2A}

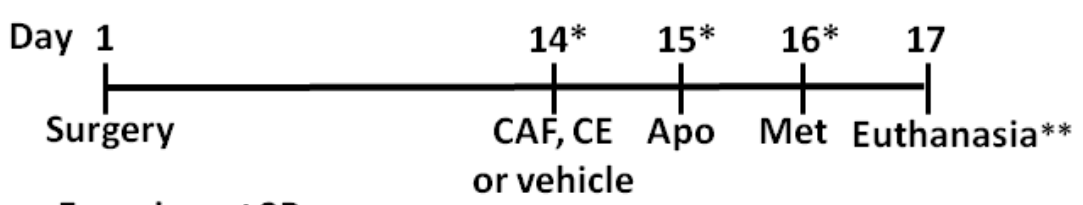

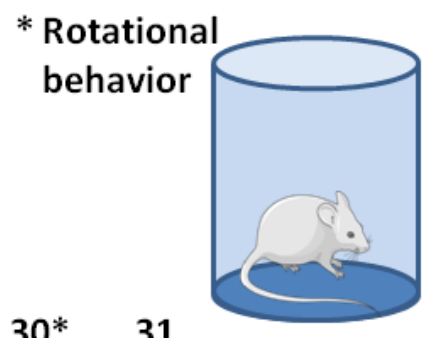

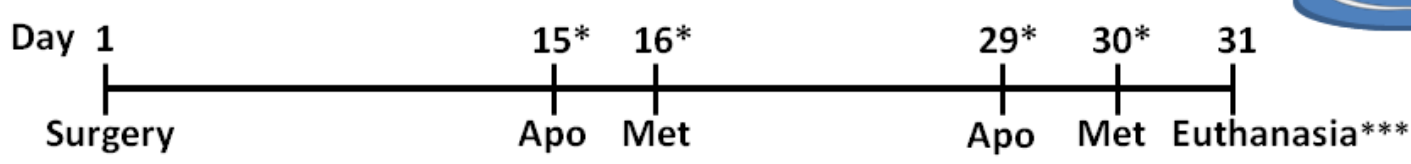

Treatment with CAF, CE or vehicle

\section{Experiment 3}

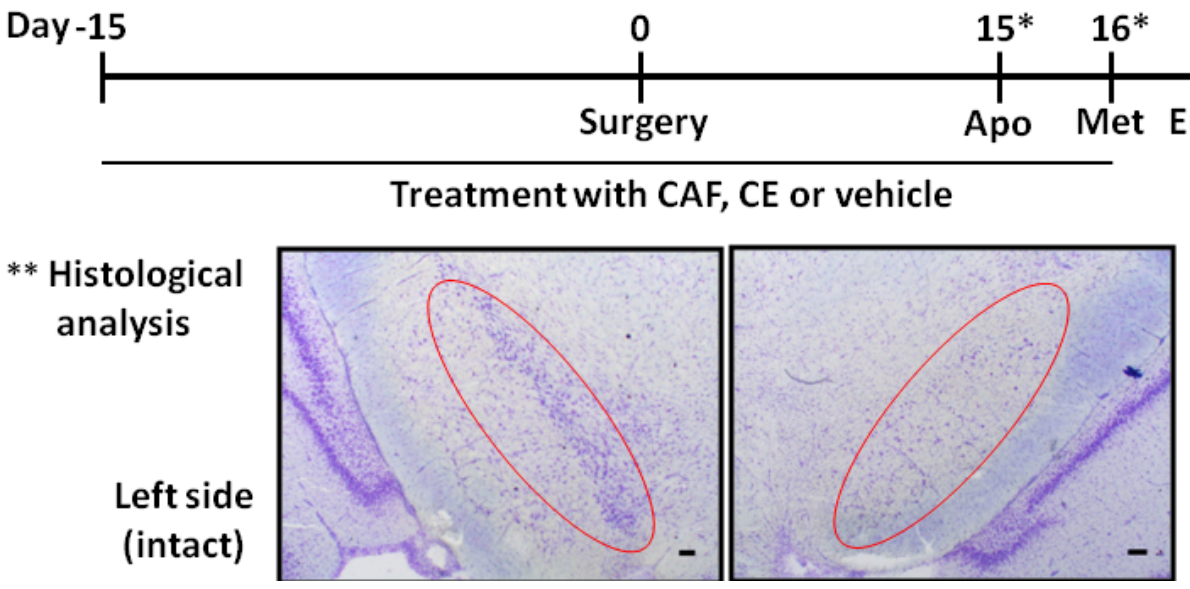

17<smiles>[CH]1[CH]C1</smiles>

Euthanasia***

Figure 1. Schematic representation of the experimental design for the 6-OHDA unilateral lesion model.

Experiments $2 \mathrm{~A}$ and $2 \mathrm{~B}$ : lesion on medial forebrain bundle (MFB); experiment 3: lesion on striatum. The low panel shows a representative photomicrograph of a coronal section submitted to cresyl violet staining. $\mathrm{CE}=\mathrm{Coffee}$ extract, $\mathrm{CAF}=$ caffeine, $\mathrm{APO}=$ apomorphine, $\mathrm{MET}=$ methamphetamine.

days, methamphetamine $(2.5 \mathrm{mg} / \mathrm{kg}$, ip) was administered and the number of rotations was once again recorded. The treatment with CE or caffeine on the days of rotational tests was made after the behavioral evaluation to avoid acute interference with apomorphine or methamphetamine.

\section{Experiment 3: Unilateral lesion on striatum -} Effect of pre- and post-treatment with CE on the rotational behavior of rats challenged with apomorphine and methamphetamine

Groups of 11-15 rats were pre-treated for 15 days with CE (100 or 400 mg/ kg), caffeine (31.2 $\mathrm{mg} / \mathrm{kg}$ ) or vehicle by gavage. One hour after treatment on day 15 the rats were submitted to the stereotaxic surgery and 6-OHDA (lesioned group) or buffered saline (sham-operated group) was administered into the right striatum. The treatment continued for another 15 days and the animals were challenged with apomorphine $\left(15^{\text {th }}\right.$ day after surgery) and methamphetamine $\left(16^{\text {th }}\right.$ day) as previously described. The treatment with CE or caffeine on the days of rotational tests was made after the behavioral evaluation to avoid acute interference with apomorphine or methamphetamine. 


\section{Central monoamines dosage by HPLC}

After 24 hours of the last behavioral evaluation, the animals from experiments $2 B$ and 3 were euthanized for brain collection, and the brains were frozen at $-80^{\circ} \mathrm{C}$. Later, the right (lesioned) and left (control) striatum were dissected, weighed, homogenized, centrifuged and then filtered in nitrocellulose membrane. Precipitates were diluted in a solution of $0.1 \mathrm{~N}$ of sodium hydroxide and evaluated for protein concentration using a colorimetric quantification kit (Pierce Chemical, Rockford, USA) and supernatants $(20 \mu \mathrm{L})$ were used for monoamines quantification through high-performance liquid chromatography (HPLC) according to method described in details by Machado et al. (2008). Each sample was analyzed in duplicate for concentrations of dopamine (DA), noradrenaline (NE), serotonin (5$\mathrm{HT}$ ) and their metabolites dihydroxyphenylacetic acid (DOPAC), homovanillic acid (HVA) and 5-hydroxyindolacetic acid (5-HIAA). The recovery rate of the analytes was determined by adding a predetermined amount of internal standard dihydroxybenzylamine for the homogenization of tissue. The peak areas of samples were compared with peak areas of standards of each neurotransmitter or metabolite, which were injected at known concentrations, at intervals between runs.

\section{Statistical analysis}

Statistical comparisons were performed using GraphPad Prism 8.3 software. Data were checked for normality distribution using Shapiro-Wilks test. Non-parametric data (rotational behavior test and monoamine levels) were analyzed using Kruskal-Wallis test followed by MannWhitney, or Wilcoxon test (to compare ipsilateral and contralateral rolations among each group); parametric-distributed data (catalepsy time) were analyzed using OneWay analysis of variance ANOVA followed by Tukey. The results are expressed as mean \pm standard error (SEM). Statistical significance was considered at $p<0.05$.

\section{RESULTS}

\section{Phytochemical analysis and caffeine dosage}

Chlorogenic acids are a family of esters formed between quinic acid and trans-cinnamic acids, such as caffeic, $p$-coumaric and ferulic acid, all of which can be esterified at one or more of the hydroxyls at positions 1, 3, 4, and 5 of quinic acid to generate a series of positional isomers. In RPHPLC, the isomers of the monocaffeoylquinic acids elute in the order of 3-, 5-, and 4-isomer and for dicaffeoylquinic acids, the elution order is 3,4-isomer, 3,5-isomer, and, finally, 4,5-isomer (Monteiro \& Farah 2012).

The main constituents found in the CE are listed in Figure S1 - Supplementary Material, together with their retention times and maximum absorption wavelength observed in their respective ultraviolet spectrum (Panusa et al. 2017). Caffeoylquinic acid and feruloylquinic acid derivatives exhibited a UV/vis maximum wavelength absorption between 310 and 330 $\mathrm{nm}$ (band I) and a shoulder between 290 and $300 \mathrm{~nm}$ (band II), while caffeine exhibited a UV/ vis maximum wavelength absorption at $272 \mathrm{~nm}$ (Hečimović et al. 2011). Caffeine was the main constituent detected at a wavelength of 272 $\mathrm{nm}$ with the retention time of 22.18 minutes, in which the percentage area corresponded to $36 \%$. Through the calibration curve, the caffeine content was calculated as $7.8 \%$.

Caffeoylquinic acid and feruloylquinic acid derivatives were the main constituents detected at a wavelength of $330 \mathrm{~nm}$, but caffeine is hardly detectable due to its low absorption at $\lambda=330$ $\mathrm{nm}$. Caffeoylquinic acid derivatives were the main constituent detected at a wavelength of $330 \mathrm{~nm}$, at 18.19 - 19.44 minutes and exhibited 
a percentage area corresponding to 69\% (Figure S1).

\section{Evaluation of antioxidant capacity}

CE inhibited the spontaneous lipid peroxidation in rat brain homogenate in vitro in a concentration-dependent way. The value of $Q_{1 / 2}$ obtained by linear regression from 4 assays was $8.73 \mu \mathrm{g} / \mathrm{mL}$.

\section{Experiment 1: Catalepsy induced by haloperidol}

Haloperidol ( $5 \mathrm{mg} / \mathrm{kg}$, ip) induced catalepsy on the vehicle control group when compared to the negative control group (Figure 2), demonstrating that the drug was effective in producing dopaminergic blockade, as expected. The acute administration of caffeine and CE (100 mg/ kg) decreased the catalepsy index (Figure 2a) when compared to the vehicle group after haloperidol injection $[F(4,58)=5.127 ; p=0.0013$ followed by Tukey $p=0.0097$ for caffeine and $p=0.0455$ for CE $100 \mathrm{mg} / \mathrm{kg}$ ]. Also, the administration for 15 days with CE (100 and $400 \mathrm{mg} / \mathrm{kg}$ ) decreased the catalepsy index in comparison to the vehicle group $[F(3,32)=6.923 ; p=0.0010$ followed by Tukey $p=0.0020$ for CE100 and $p=0.0262$ for CE $400 \mathrm{mg} /$ $\mathrm{kg}$ ] (Figure 2b). a

Acute

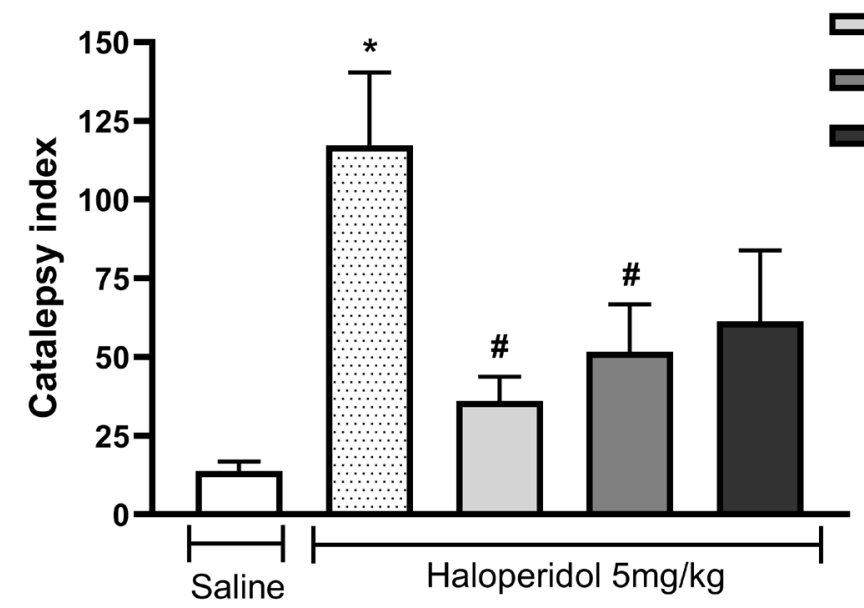

b

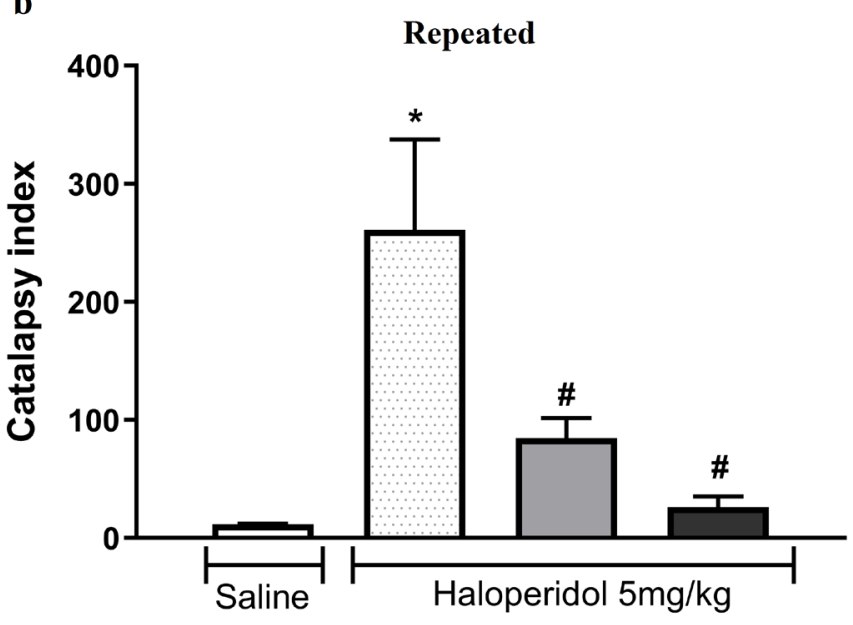

Negative control

W... Vehicle

Caffeine $31.2 \mathrm{mg} / \mathrm{kg}$

ㄷ $100 \mathrm{mg} / \mathrm{kg}$

CE $400 \mathrm{mg} / \mathrm{kg}$
Figure 2. CE and caffeine avoid the cataleptic effect induced by haloperidol (5 mg/ kg, ip). a) acute treatment with coffee extract (CE 100 or 400 mg/ $\mathrm{kg}, \mathrm{po}$ ) or caffeine (31.2 $\mathrm{mg} / \mathrm{kg}, \mathrm{po}) \mathrm{b}$ ) repeated treatment (15 days) with coffee extract (CE 100 or $400 \mathrm{mg} / \mathrm{kg}, \mathrm{po}$ ). Catalepsy index (catalepsy time) number of times the mouse went down the bar). Data are expressed as mean \pm standard error of mean, $n=6-13 .{ }^{*} p<0.05$ statistically different from negative control group; ${ }^{*} p<0.05$ statistically different from haloperidol-vehicle control (ANOVA followed by Tukey). 
Unilateral lesion induced by 6-OHDA

\section{Experiment 2A: Effect of the acute treatment} with CE, apomorphine and methamphetamine on the rotational behavior of rats with lesion on MFB

Rats with unilateral lesion on MFB were acutely challenged with vehicle, caffeine or CE ( $14^{\text {th }}$ day), apomorphine ( $\left.15^{\text {th }} \mathrm{day}\right)$, and methamphetamine $\left(16^{\text {th }}\right.$ day). The challenge with caffeine and CE
$400 \mathrm{mg} / \mathrm{kg}$ increased the number of ipsilateral rotations on lesioned rats, compared with lesioned rats treated with vehicle $(H=15.104$; $p=0.004$ followed by Mann-Whitney $p=0.0218$ for caffeine and $p=0.0145$ for CE $400 \mathrm{mg} / \mathrm{kg}$ ), but it did not alter the number of contralateral rotations, as shown in Figure 3a. There was significant difference between the number of contralateral and ipsilateral rotations in the

a

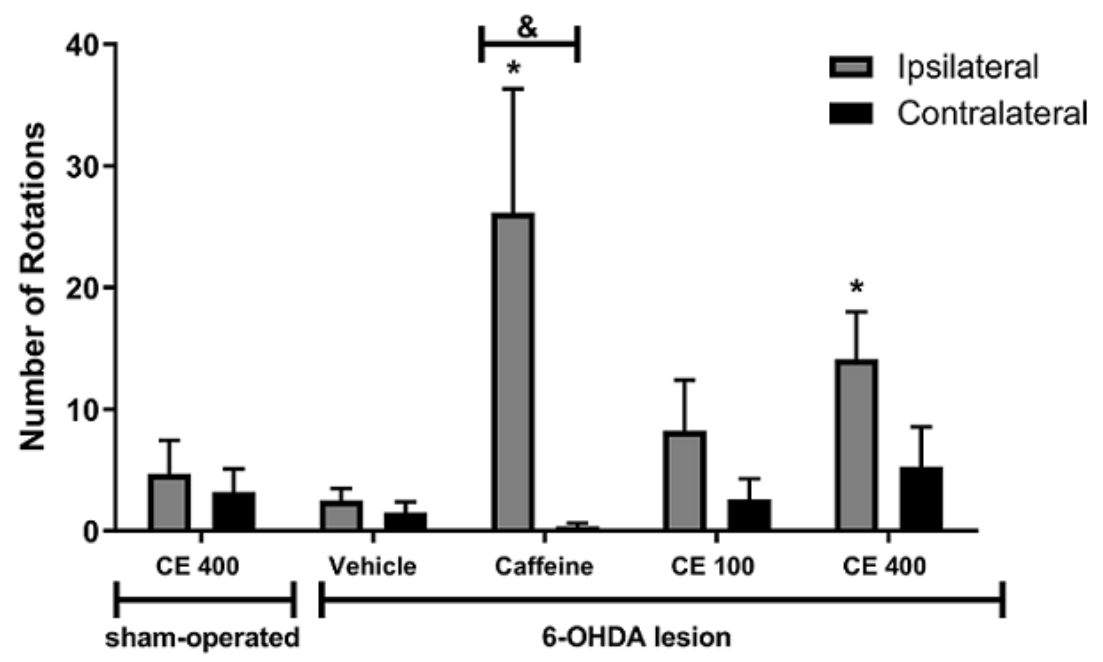

b

Challenge with apomorphine

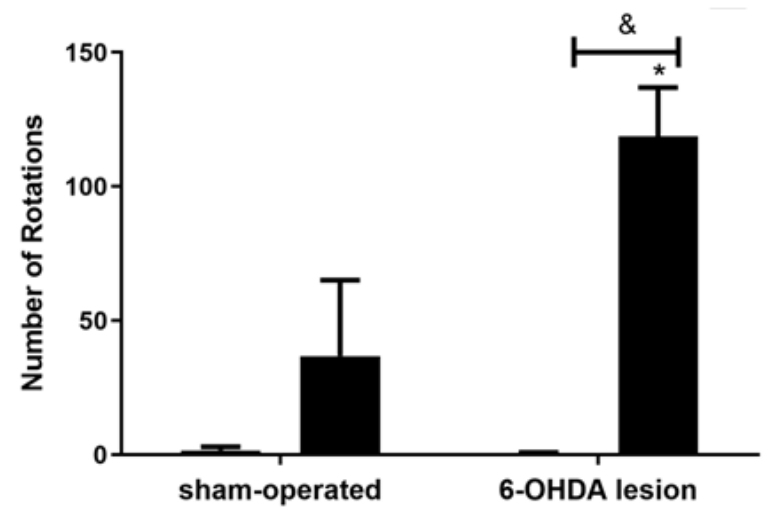

c Challenge with methamphetamine $\square$ Ipsilateral

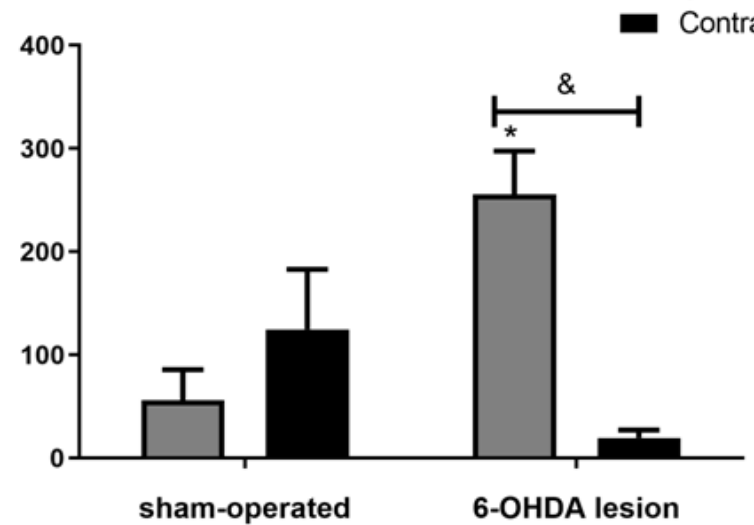

Figure 3. Caffeine, CE (400 mg/ kg), and methamphetamine induce ipsilateral rotations, and apomorphine induces contralateral rotations in rats with 6-OHDA unilateral lesion of medial forebrain bundle (MFB). a) $14^{\text {th }}$ day challenged with coffee extract (CE 100 or $400 \mathrm{mg} / \mathrm{kg}, \mathrm{po})$, caffeine $\left(31.2 \mathrm{mg} / \mathrm{kg}, \mathrm{po}\right.$ ) or vehicle. b) $15^{\text {th }}$ day challenged with apomorphine $(0.1 \mathrm{mg} / \mathrm{kg}, \mathrm{sc}) . \mathrm{c}) 16^{\text {th }}$ day challenged with methamphetamine $(2.5 \mathrm{mg} / \mathrm{kg}, \mathrm{ip}) . \mathrm{Data}$ are expressed as mean \pm standard error of mean, $n=10-15 .{ }^{*} p<0.05$ statistically different from vehicle (KruskallWallis/Mann-Whitney, panel a) or sham-operated group (Mann-Whitney, panels b and c); ${ }^{2} p<0.05$ statistically different when comparing ipsilateral vs contralateral (intra-group comparison, Wilcoxon). 
group's caffeine (Wilcoxon, $p=0.0078$ ) but not in the other groups.

The lesion induced by 6-OHDA was effective in inducing contralateral rotations after apomorphine $(U=811 ; p<0.0001)$ or ipsilateral rotations after methamphetamine $(U=624.5$; $p<0.0001)$ administration when compared to sham-operated group, as can be observed in Figure $3 \mathrm{~b}$ and Figure $3 \mathrm{c}$, respectively.

\section{Experiment 2B: Effect of repeated treatment with CE on the rotational behavior of rats with lesion on MFB challenged with apomorphine and methamphetamine}

The effect of repeated treatment with CE on the rotational behavior of rats with right lesion of MFB was evaluated after challenge with apomorphine (15 $5^{\text {th }}$ and $29^{\text {th }}$ days) and methamphetamine ( $16^{\text {th }}$ and $30^{\text {rd }}$ days). Figure $4 \mathrm{a}$ shows that apomorphine induced contralateral rotations in all MFB experimental lesioned groups when compared to sham-operated group on $15^{\text {th }}$ day $(H=22.545 ; p=0.0002$ followed by Mann-Whitney $p<0.05$ ). The same result was observed at ipsilateral rotations induced by methamphetamine on $16^{\text {th }}$-day $(H=22.280$; $p=0.0002$ followed by Mann-Whitney $p<0.05$ ) (Figure 4b). However, neither CE nor caffeine treatment changed the rotational behavior when compared with vehicle control group both after apomorphine and methamphetamine challenge $(p>0.05)$. Similar results were observed on the $29^{\text {th }}$ day with apomorphine (Figure $4 \mathrm{c}$ ) and $30^{\text {rd }}$ day with methamphetamine (Figure $4 \mathrm{~d}$ ) and a

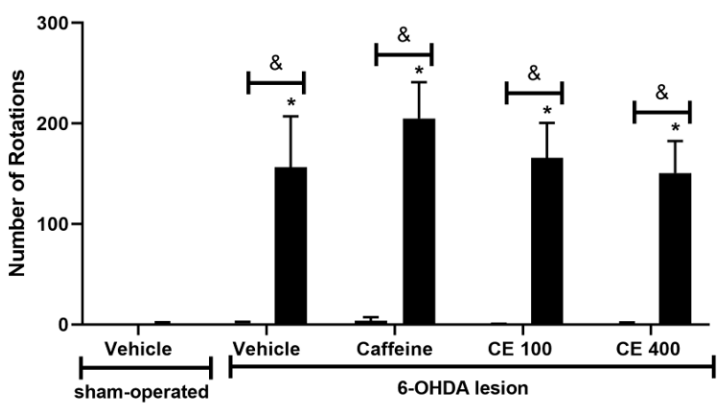

c

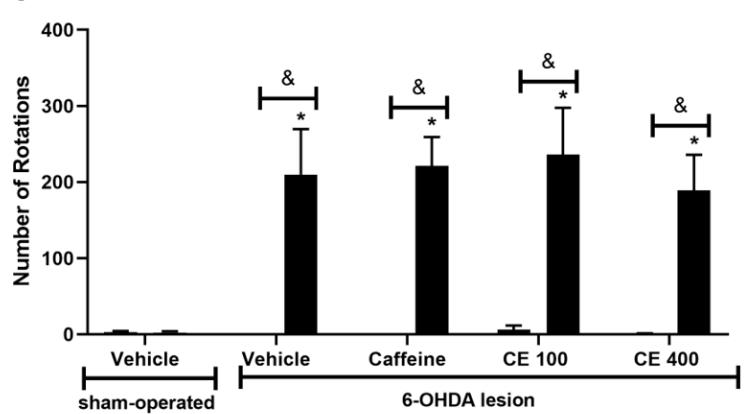

b

Challenge with methamphetamine

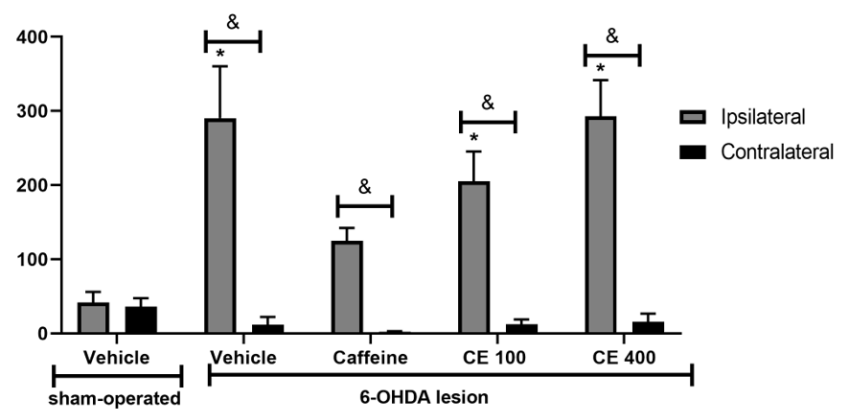

d

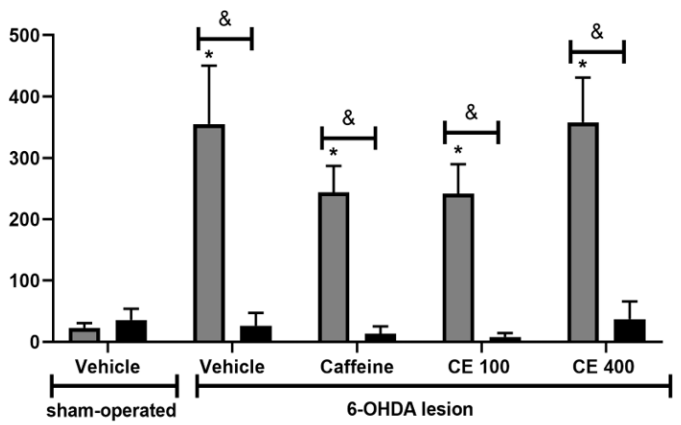

Figure 4. Repeated treatment with CE or caffeine do not affect the rotational behavior induced by apomorphine $(0.1 \mathrm{mg} / \mathrm{kg}, \mathrm{sc})$ and methamphetamine $(2.5 \mathrm{mg} / \mathrm{kg}$, ip) in rats with 6-OHDA unilateral lesion of medial forebrain bundle (MFB). a) apomorphine challenge in the $15^{\text {th }}$ day. b) methamphetamine challenge in the $16^{\text {th }}$ day. $c$ ) apomorphine challenge in the $29^{\text {th }}$ day. d) methamphetamine challenge in the $30^{\text {rd }}$ day. Data are expressed as mean \pm standard error of mean, $n=12-15$. ${ }^{*} p<0.05$ statistically different from sham-operated group (KruskallWallis/Mann-Whitney). ${ }^{\&} p<0.05$ statistically different when comparing ipsilateral vs contralateral (intra-group comparison, Wilcoxon). 
these results were not altered by CE or caffeine treatment ( $p>0.05)$.

\section{Experiment 3: Effect of pre- and post-} treatment with CE on the rotational behavior of rats with striatal lesion challenged with apomorphine and methamphetamine

Rats were pre-treated with CE or caffeine for 15 days before the surgery and then for more 15 days after striatal lesion, prior the rotational evaluation. Typical rotations were observed after apomorphine $(0.1 \mathrm{mg} /$ $\mathrm{kg}, \mathrm{sc}$ ) or methamphetamine $(2.5 \mathrm{mg} / \mathrm{kg}$, ip) administration on vehicle control rats with striatal lesion, although the statistical analysis has not shown differences when compared with sham-operated group, due to the great variability observed (Figure 5a and Figure 5b). On the other hand, statistical difference was observed between ipsilateral and contralateral rotation for the vehicle control group challenged with apomorphine (Wilcoxon $p=0.0151$ ). Also, the number of ipsilateral rotations was more than twice that of contralateral rotations for the vehicle control group, but the values were not statistically significant (Wilcoxon $p=0.2136$ ).

Lesioned rats treated with CE or caffeine did not differ from the sham-operated group as the a

Challenge with apomorphine

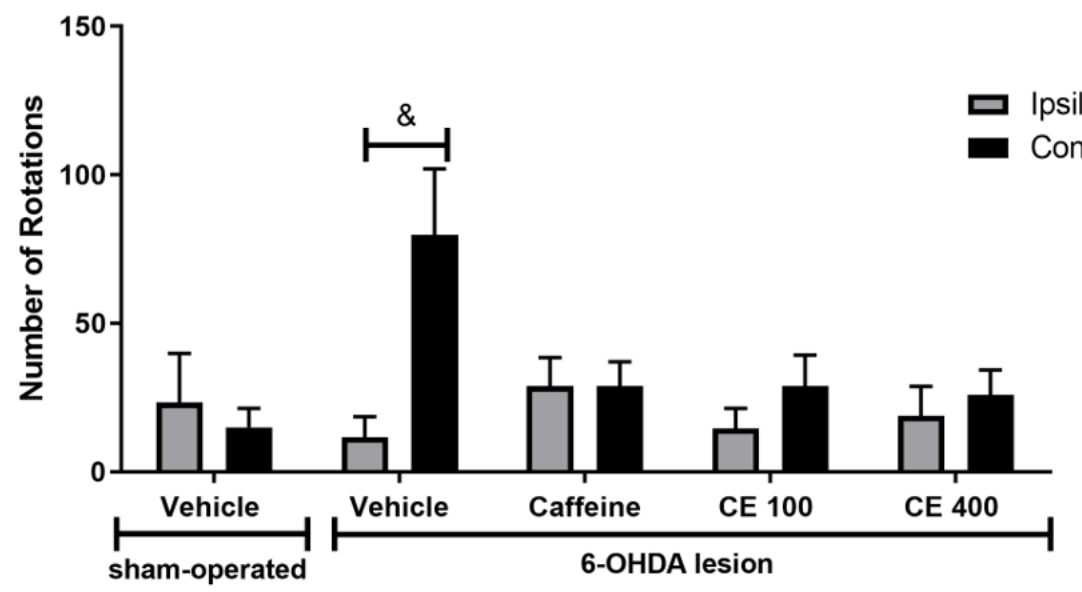

b

Challenge with methamphetamine

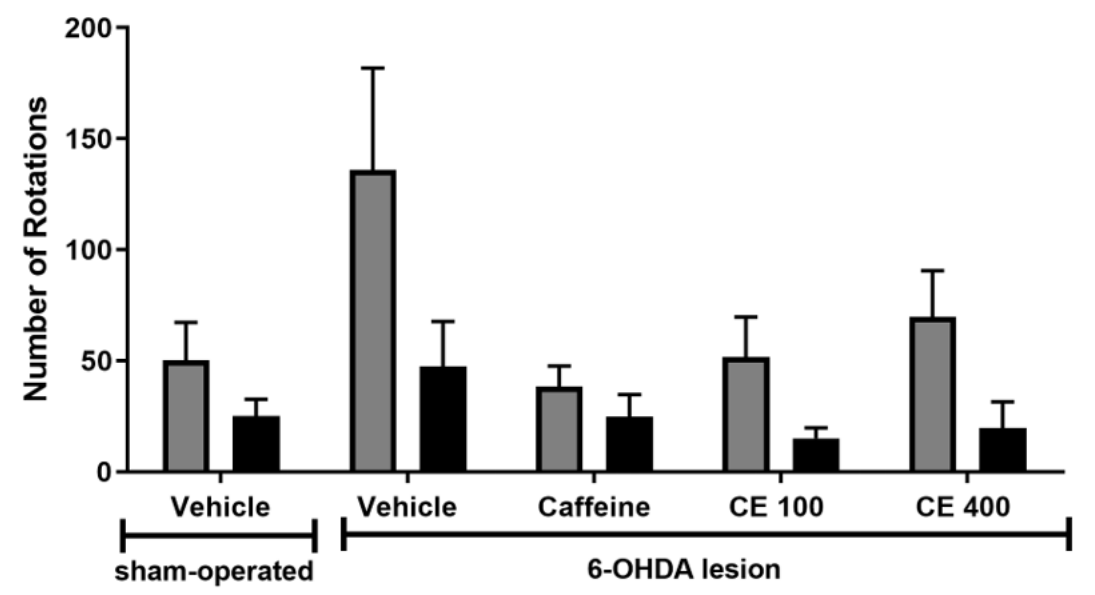

Figure 5. Repeated treatment with CE or caffeine inhibit the unbalance between ipsilateral and contralateral rotations induced by apomorphine $(0.1 \mathrm{mg} / \mathrm{kg}$, sc) and methamphetamine $(2.5 \mathrm{mg} / \mathrm{kg}$, ip) in rats with 6-OHDA unilateral lesion of striatum. a) Apomorphine challenge ( $15^{\text {th }}$ day). b) Methamphetamine challenge (16 ${ }^{\text {th }}$ day). Data are expressed as mean \pm standard error of mean, $n=11-15$. KruskalWallis $p>0.05$, n.s. (intergroup comparisons); ${ }^{\&} p<0.05$ statistically different when comparing ipsilateral vs contralateral (intra-group comparison, Wilcoxon). 
number of rotations and there was no difference between contralateral and ipsilateral rotations on intra-group comparison (Figure $5 \mathrm{a}$ and Figure $5 b)$.

\section{Central monoamines dosage by HPLC}

Table I shows the monoamine levels measured on the right and the left striatum of animals with MFB lesion and non-lesioned rats (shamoperated group). There is an apparent decrease of DA, NE, 5-HT and some of their metabolites on vehicle lesioned group when compared to sham-operated group on right striatum, but the values were not statistically significant $(p>0.05)$. Nevertheless, the treatments with CE or caffeine did not change the levels of monoamines. No significant effects were observed on the left (non-lesioned) side.

Table II shows the quantification of monoamines in the right (lesioned) and left (control) striatum of rats with striatal lesion and sham-operated animals. No significant changes ( $p>0.05$ ) were observed regarding quantification of neurotransmitters or their metabolites in both hemispheres (comparison among groups).

\section{DISCUSSION}

Epidemiological studies have shown an inverse correlation between regular coffee intake and development of Parkinson's disease (Costa et al. 2010, Hu et al. 2007, Qi \& Li 2014, Ross et al. 2000). Experimental studies support the

Table I. Treatments with CE or caffeine do not change the levels of monoamines compared to control group. Monoamines dosage (HPLC) in the right and left striatum of animals with lesion in the right side of medial forebrain bundle (MFB) and in sham-operated animals. Data are expressed as mean \pm standard error of mean $(n=4-7)$.

\begin{tabular}{|c|c|c|c|c|c|c|}
\hline \multirow{2}{*}{$\begin{array}{l}\text { Treatment } \\
\text { (right side) }\end{array}$} & \multicolumn{6}{|c|}{ Monoamines / metabolites (ng/mg protein) } \\
\hline & NE & DA & DOPAC & HVA & 5-HT & 5-HIAA \\
\hline Sham-operated & $8.66 \pm 2.00$ & $71.44 \pm 14.71$ & $15.16 \pm 9.61$ & $3.83 \pm 0.83$ & $9.89 \pm 0.63$ & $5.81 \pm 0.72$ \\
\hline Vehicle & $5.49 \pm 1.87$ & $34.37 \pm 15.83$ & $4.30 \pm 1.79$ & $2.98 \pm 0.83$ & $12.55 \pm 3.04$ & $8.47 \pm 2.13$ \\
\hline Caffeine $31.2 \mathrm{mg} / \mathrm{kg}$ & $7.54 \pm 2.81$ & $35.60 \pm 15.66$ & $4.12 \pm 1.37$ & $3.04 \pm 1.34$ & $11.83 \pm 1.95$ & $6.28 \pm 1.67$ \\
\hline CE $100 \mathrm{mg} / \mathrm{kg}$ & $3.77 \pm 0.32$ & $32.84 \pm 15.26$ & $2.50 \pm 0.89$ & $1.88 \pm 0.67$ & $11.23 \pm 0.83$ & $13.90 \pm 6.00$ \\
\hline CE $400 \mathrm{mg} / \mathrm{kg}$ & $3.16 \pm 1.22$ & $42.45 \pm 20.35$ & $3.88 \pm 1.46$ & $1.91 \pm 0.78$ & $11.27 \pm 2.26$ & $8.83 \pm 2.03$ \\
\hline (left side) & NE & DA & DOPAC & HVA & 5-HT & 5-HIAA \\
\hline Sham-operated & $6.49 \pm 1.35$ & $57.76 \pm 13.80$ & $3.98 \pm 0.88$ & $1.49 \pm 0.48$ & $10.05 \pm 1.72$ & $5.25 \pm 1.04$ \\
\hline Vehicle & $4.67 \pm 0.86$ & $62.18 \pm 7.33$ & $4.53 \pm 0.37$ & $2.01 \pm 0.32$ & $9.87 \pm 0.89$ & $5.97 \pm 0.82$ \\
\hline Caffeine $31.2 \mathrm{mg} / \mathrm{kg}$ & $6.00 \pm 1.97$ & $64.35 \pm 18.26$ & $5.70 \pm 1.50$ & $3.47 \pm 1.51$ & $12.15 \pm 2.90$ & $4.63 \pm 1.77$ \\
\hline CE $100 \mathrm{mg} / \mathrm{kg}$ & $4.95 \pm 0.42$ & $134.15 \pm 15.06$ & $8.09 \pm 1.13$ & $4.41 \pm 0.98$ & $9.87 \pm 1.18$ & $10.76 \pm 3.75$ \\
\hline CE $400 \mathrm{mg} / \mathrm{kg}$ & $8.54 \pm 3.14$ & $80.46 \pm 24.89$ & $6.43 \pm 2.10$ & $3.46 \pm 0.91$ & $8.98 \pm 2.07$ & $6.54 \pm 1.75$ \\
\hline
\end{tabular}

Kruskal-Wallis (n.s.). 
neuroprotective effect of caffeine through its adenosinergic antagonism (Chen et al. 2001, Kelsey et al. 2009, Xu et al. 2010) and also suggest that other mechanisms might contribute to this protective action, such as the anti-inflammatory effect, inhibition of $\alpha$-synuclein aggregation and modulation of other pathways (Luan et al. 2018, Machado-Filho et al. 2014, Mancini et al. 2018).

It is known that antioxidant compounds can potentially decrease the progression of neurodegenerative diseases such as Alzheimer's disease and PD, in which oxidative stress participates in the induction of cell death process (Di Matteo \& Esposito 2003, Pohl \& Lin 2018). The phytochemical analysis confirmed that the green coffee extract employed in the current study is rich in chlorogenic acids (caffeoylquinic acid and feruloylquinic acid derivatives). The content of caffeine was calculated in $7.8 \%$ and used to define the dose of caffeine group in the behavioral tests. The amount of caffeine and chlorogenic acids in commercial samples reported in literature varies depending on the coffee species and method of preparation, with higher contents of caffeine found in instant roasted coffee (Jeon et al. 2019) and chlorogenic acids in green coffee infusions (Macheiner et al. 2019).

The antioxidant activity of the green CE was confirmed in our study using rat brain homogenates by the lipid peroxidation assay. Previous studies compared the antioxidant capacity of green and roasted coffee in different tests. The literature is controversial about the effect of roasting process on the antioxidant capacity of coffee, but some studies suggest

Table II. Treatments with CE or caffeine do not change the levels of monoamines compared to control group. Monoamines dosage (HPLC) in the right and left striatum of animals with lesion in the right side of striatum and in sham-operated animals. Data are expressed as mean \pm standard error of mean $(n=7-8)$.

\begin{tabular}{|c|c|c|c|c|c|c|}
\hline \multirow{2}{*}{ Treatment } & \multicolumn{5}{|c|}{ Monoamines / metabolites (ng/mg protein) } \\
\hline (right side) & NE & DA & DOPAC & HVA & 5-HT & 5-HIAA \\
\hline Sham-operated & $30.97 \pm 14.09$ & $110.08 \pm 18.08$ & $20.08 \pm 6.78$ & $17.97 \pm 7.83$ & $21.72 \pm 7.64$ & $18.81 \pm 7.42$ \\
\hline Vehicle & $12.49 \pm 4.38$ & $65.29 \pm 13.69$ & $6.44 \pm 1.16$ & $4.85 \pm 0.82$ & $6.88 \pm 1.41$ & $5.30 \pm 1.14$ \\
\hline Caffeine 31.2 mg/kg & $13.40 \pm 2.22$ & $54.76 \pm 16.61$ & $6.17 \pm 1.88$ & $4.68 \pm 1.27$ & $9.00 \pm 2.65$ & $6.02 \pm 1.76$ \\
\hline CE 100 mg/kg & $8.79 \pm 3.01$ & $68.94 \pm 9.34$ & $6.75 \pm 0.97$ & $4.38 \pm 0.97$ & $7.79 \pm 0.88$ & $4.80 \pm 1.12$ \\
\hline CE 400mg/kg & $16.94 \pm 9.82$ & $72.13 \pm 17.47$ & $10.20 \pm 5.86$ & $9.32 \pm 6.79$ & $13.27 \pm 5.77$ & $9.69 \pm 5.71$ \\
\hline (left side) & $\mathbf{N E}$ & $\mathbf{D A}$ & $\mathbf{D O P A C}$ & HVA & $\mathbf{5}-\mathbf{H T}$ & $\mathbf{5}-\mathbf{H I A A}$ \\
\hline Sham-operated & $11.66 \pm 2.89$ & $79.32 \pm 18.32$ & $7.28 \pm 1.51$ & $3.37 \pm 1.15$ & $7.06 \pm 1.15$ & $4.50 \pm 1.17$ \\
\hline Vehicle & $5.71 \pm 1.18$ & $71.90 \pm 16.76$ & $5.91 \pm 1.57$ & $2.51 \pm 0.86$ & $4.92 \pm 1.32$ & $3.71 \pm 1.04$ \\
\hline Caffeine 31.2 mg/kg & $12.31 \pm 2.28$ & $59.74 \pm 20.98$ & $4.58 \pm 1.78$ & $2.28 \pm 0.84$ & $7.09 \pm 1.69$ & $5.71 \pm 1.88$ \\
\hline CE 100 mg/kg & $6.49 \pm 1.57$ & $79.50 \pm 15.75$ & $7.94 \pm 1.93$ & $4.33 \pm 1.04$ & $9.26 \pm 1.17$ & $5.35 \pm 1.23$ \\
\hline CE 400 mg/kg & $15.91 \pm 9.50$ & $59.07 \pm 12.63$ & $3.69 \pm 0.79$ & $1.08 \pm 0.37$ & $6.12 \pm 1.07$ & $2.77 \pm 0.80$ \\
\hline
\end{tabular}

Kruskal-Wallis (n.s). 
that melanoidins and other compounds formed during the roasting also present elevated antioxidant capacity (Chu et al. 2009, Daglia et al. 2000, Mancini et al. 2018, Priftis et al. 2015, Wolska et al. 2017). Daglia et al. (2000) showed that green coffee presented higher antioxidant activity on beta carotene-linoleic acid in vitro assay, while roasted coffee was more potent on lipid peroxidation assay. This divergence could be explained by the difference in the species or varieties of coffee, the type of extract, preparation method, roasting time and methodologies used to evaluate the antioxidant activity (Priftis et al. 2015, Wolska et al. 2017, Socała et al. 2020).

PD is characterized primordially as a motor dysfunction, and catalepsy and akinesia induced by haloperidol have been used as animal models of PD and to study pro- and anti-dopaminergic drugs. Moo-Puc et al. (2003) observed an anticataleptic effect in rats treated with low doses of caffeine and suggested that caffeine could be an adjunctive therapy to reduce the doses of anticholinergics drugs in PD. Another study showed that chronic consumption of caffeine on drinking water for 6 months produced perdurable resistance to catalepsy induced by haloperidol in rats (Góngora-Alfaro et al. 2009). Selective adenosine $A_{2}$ antagonists are able to reduce the effect of haloperidol confirming the antagonistic interaction between adenosine $A_{2 A}$ and dopamine $D_{2}$ receptors and suggesting the involvement of adenosine $A_{2}$ receptors in the mechanisms of catalepsy (Malec 1997). The green CE used in our study probably exerts an indirect action on the dopaminergic system, demonstrated by inhibition of haloperidolinduced catalepsy, which was more evident after repeated treatment for 15 days with CE at $400 \mathrm{mg} /$ $\mathrm{kg}$, suggesting that there was no tolerance with repeated administration. Such result, combined with experimental studies of caffeine and other coffee components as neuroprotective agents
(Chen et al. 2001, Kelsey et al. 2009, Lee et al. 2013, Teraoka et al. 2012, Xu et al. 2010, Yan et al. 2018) support the assumption of beneficial effect of coffee on PD. To evaluate this hypothesis, we produced unilateral lesion on nigrostriatal dopaminergic pathway by injection of 6-OHDA neurotoxin in MFB and striatum.

The rotational behavior model after unilateral lesion with 6-OHDA is one of the most used animal models to study PD and drugs with potential neuroprotective effect (lancu et al. 2005, Kaczyńska \& Andrzejewski 2020, Schwarting \& Huston 1996, Ungerstedt \& Arbuthnott 1970). The unilateral lesion leads to unbalance of dopaminergic neurotransmission between left and right striatum which can be evaluated after challenge with dopaminergic drugs, such as apomorphine and amphetamine. Our data indicate that lesioned animals had the expected rotational behavior when challenged with apomorphine and methamphetamine, in accordance with data from literature (Da Cunha et al. 2008, Lane et al. 2006, Yuan et al. 2005). The fact that animals challenged with CE presented ipsilateral rotations provides evidence of its action on the dopaminergic system, indicating an effect similar to methamphetamine, an indirect agonist. Cauli et al. (2003) showed that the administrations of caffeine for two weeks could increase dopamine release in the intact side of the striatum, consistent with the ipsilateral direction of the rotational behavior. Moreover, it has been shown that caffeine does not bind to dopamine receptors, suggesting that this action has occurred by indirect mechanism, such as adenosinergic modulation. Furthermore, other coffee constituents would also be responsible for the observed effect.

The effects of the repeated treatment with CE before the challenge with apomorphine and methamphetamine were also analyzed. The treatment started 24 hours after the MFB injury 
with 6-OHDA and the animals were treated for 30 days with the objective of evaluating whether the treatments could exert a neuroprotective effect and avoid the asymmetry on the rotational test. There was no difference in the type and number of rotations among different experimental groups, including the caffeine group. This result does not corroborate with a previous study in which caffeine $(15 \mathrm{mg} /$ $\mathrm{kg}$, ip) given acutely partially prevented the impairment of contralateral forepaw stepping in rats with MFB unilateral lesion induced by 6-OHDA (Aguiar et al. 2006). These authors also found a similar effect after acute injection of caffeine at dorsal striatum and external globus pallidus (20-40 $\mu \mathrm{g})$, but in both studies the authors evaluated only the behavioral response 20 minutes before the test, while the lesion itself was not quantified. Bové et al. (2005) discuss that the dose and number of sites of 6-OHDA may produce different effects, making difficult to compare studies using different protocols. The route of administration, dose and time of treatment with the experimental drug are also fundamental to achieve the drug efficacy.

We also evaluated the effect of CE and caffeine in the rotational behavior of rats with 6-OHDA unilateral lesion in the striatum. In this experiment, the rats were pre-treated for 15 days before the surgery and additionally for 15 days after the lesion. The animals from the control lesioned-group presented a suggestive increase in the contralateral and ipsilateral rotations (after apomorphine and methamphetamine challenge, respectively) compared to shamoperated group, although the statistical analysis did not indicate significant differences. The intra-group comparison showed that the vehicle control group presented difference between ipsilateral and contralateral rotations after apomorphine challenge. On the other hand, the rats treated with CE or caffeine showed behavior similar to those of sham-operated group, where the number of ipsilateral and contralateral rotations was equivalent. This data may suggest that the treatment was able to compensate the unbalance between right and left striatum by indirect mechanisms, which would indicate some level of neuroprotection. This result is in agreement with Machado-Filho et al. (2014) which employed the same experimental model and observed that caffeine (10-20 mg/ kg) given orally for two weeks moderately reduced the contralateral rotations induced by apomorphine. The content of caffeine in our study was 7.8 and $31.2 \mathrm{mg} / \mathrm{kg}$ in CE 100 and CE $400 \mathrm{mg} / \mathrm{kg}$, respectively. The neuroprotective effect of caffeine was also observed in studies using the neurotoxin 1-methyl-4-phenyl-1,2,3,6tetrahydropyridine (MPTP) (Chen et al. 2001, Xu et al. 2010).

The contents of monoamines and their metabolites were measured in the left and right striatum of the rats with lesion on right MFB (experiment 2B) and right striatum (experiment 3). In the first study the levels of DA and NE were moderately reduced in the lesioned side in the vehicle-control group when compared to the sham-operated group (decrease of 52.1 and 44.5\%, respectively), although the difference was not significant. However, the levels of neurotransmitters or metabolites of rats treated with CE and caffeine did not differ from the vehicle control group. This suggest that the treatment was not efficient in protecting nigrostriatal neurons from 6-OHDA.

Regarding the second experiment, the levels of DA, NE, 5-HT and its metabolites seemed decreased on lesioned control group (vehicle) in comparison with the sham-operated group, but there was no significant difference. The levels of DA and NE were reduced in 59.1 and $61.3 \%$, respectively. Moreover, the experimental groups treated with CE or caffeine showed levels 
of neurotransmitters and metabolites similar to the vehicle, indicating that the treatments did not prevent the reduction of monoamines in the lesioned striatum. This result is in contrast with the behavioral data, but it may suggest that the effect of CE and caffeine on the rotational behavior is not dependent on the dopamine level and neuronal integrity. The decrease of NE levels in both experiments may be explained because we did not give a pre-administration of desipramine or other NE transporter inhibitor to the animals (Da Cunha et al. 2008). As result, our protocol allowed the uptake of 6-OHDA neurotoxin both by dopaminergic and by noradrenergic neurons causing non selective oxidative stress and neuronal death of catecholaminergic neurons. This protocol reproduces an advanced stage of PD in which there is pronounced loss of NA neurons, but it has the disadvantage of producing some interference in the behavioral tests.

Several studies have shown that caffeine is able to reduce the contralateral rotations induced by apomorphine, the lesion size and can attenuate the dopamine depletion after 6-OHDA injury (Aguiar et al. 2006, Bata-García et al. 2007, Kelsey et al. 2009, Machado-Filho et al. 2014) and can protect the neuronal loss induced by MPTP or other neurotoxins (Chen et al. 2001, Kachroo et al. 2010, Xu et al. 2010). Other substances present in green coffee were also evaluated on different cellular and animal models of PD (Nabavi et al. 2016, Taram et al. 2016). The chlorogenic acid protected PC12 cells against $\alpha$-synuclein (Teraoka et al. 2012), reduced the oxidative stress and neuroinflammation in MPTPintoxicated mice (Singh et al. 2018), prevented rotenone-induced neurodegeneration in nigral dopaminergic neurons (Miyazaki et al. 2019) and prevented the behavioral impairments induced by 6-OHDA in rats (Shan et al. 2019). Yan et al. (2018) evaluated the effect of low doses of caffeine and eicosanoyl-5-hydroxytryptamide (EHT) in two PD models: transgenic mice expressing human $\alpha$-synuclein and striatal injection of $\alpha$-synuclein pre-formed fibrils in mice. The combination of the two components for 6 months was effective in normalizing the biochemical and histological parameters analyzed and in promoting improvement in behavioral tasks, while caffeine or EHT alone were ineffective or produced only moderated results (Yan et al. 2018). In another study, the EHT showed protective effect against the toxin MPTP in vivo and $\mathrm{MPP}^{+}$in vitro (Lee et al. 2013). The treatment with caffeic acid partially inhibited the inflammatory process in mice that received MPTP, evaluated by the level and expression of pro-inflammatory cytokines (Tsai et al. 2011). Other studies employing decaffeinated coffee extracts also observed protective effects in cell culture and animal models, in agreement with the hypothesis that other compounds are relevant and occasionally more important than caffeine on the coffee beneficial effects (Cho et al. 2009, Lee et al. 2016, Mancini et al. 2018). Based on the literature and on our results, we propose that caffeine and other coffee compounds could act in different targets modulating the dopaminergic neurotransmission and motor function.

An important limitation of our study is that we did not quantify the extension and severity of the lesion induced by 6-OHDA regarding the neuronal death. The neuronal loss on substantia nigra was qualitatively confirmed for rats from experiment 2, which brains were sectioned and submitted to cresyl violet staining (Figure 1). This data confirm that the protocol produced neuronal death in substantia nigra, but it is not enough to evaluate the coffee effect. In experiments $2 \mathrm{~B}$ and 3 , we measured the levels of monoamine and their metabolites in the striatum as an indirect measure of neuronal death. Despite the 
high variability found, it was evident that the lesion protocol produced marked reduction in the levels of dopamine in the striatum of the lesioned hemisphere in control animals and CE was not able to avoid the reduction of dopamine level. Also, the lack of statistical difference in the rotational behavior and monoamine dosages among the experimental groups contrast to the observational data obtained. The great variability among the animals' behavior and in the monoamines dosage is also justified because we used Wistar rats, an outbread stock with genetic variability and because we could not select the animals after the behavioral tests, since CE was given as pre-treatment. Deumens et al. (2002) argue that one of the limitations on 6-OHDA lesion model is the great variability observed among the lesioned animals, what makes it difficult to find statistical differences. The rotation model induced by unilateral lesion with neurotoxins, although widely used, have a certain complexity regarding the effects observed. Different and even opposite results may be observed depending on the neurotoxin used, the local of injury, number of site infusions, and the extent of neuronal death (Kaczyńska \& Andrzejewski 2020, Schwarting \& Huston 1996). Future studies should investigate the effect of green extract and its isolated components on lesion size after 6-OHDA or other neurotoxins employing different concentrations of extract and toxin and exploring different pathways.

The results found in the present study are in line with the hypothesis that CE components were able to modulate the dopaminergic transmission by indirect pathway, observed by the inhibition of haloperidol induced catalepsy in mice and blockade of contralateral rotation after apomorphine challenge in rats with unilateral lesion of striatum. Taken together, our results suggest a pro-dopaminergic action of the $\mathrm{CE}$, but its mechanism remains unclear and insufficient to predict whether unroasted coffee would indeed have a neuroprotective effect on PD.

\section{Acknowledgments}

The authors are grateful to Dr. Ricardo B. Machado for helpful assistance in the brain monoamine analysis, to Fundação de Amparo à Pesquisa do Estado de São Paulo, Brazil (FAPESP \#06/58692-1), and Associação Fundo de Incentivo à Pesquisa (AFIP), Brazil, for financial support. This study is dedicated to the memory of Professor Emeritus Elisaldo A. Carlini.

\section{REFERENCES}

AGUIAR LMV, NOBRE HV, MACÊDO, DS, OLIVEIRA, AA, FREITAS RM, VASCONCELOS SM, CUNHA GMA, SOUSA FCF \& VIANA GSB. 2006. Neuroprotective effects of caffeine in the model of 6-hydroxydopamine lesion in rats. Pharmacol Biochem Behav 84: 415-419.

BATA-GARCÍA JL, VILLANUEVA-TOLEDO J, GUTIÉRREZ-OSPINA G, ÁLVAREZ-CERVERA FJ, HEREDIA-LÓPEZ FJ \& GÓNGORA-ALFARO JL. 2007. Sustained improvement of motor function in hemiparkinsonian rats chronically treated with low doses of caffeine or trihexyphenidyl. Pharmacol Biochem Behav 86: 68-78.

BJÖRKLUND A \& DUNNETT SB. 2019. The amphetamine induced rotation test: A re-assessment of its use as a tool to monitor motor impairment and functional recovery in rodent models of Parkinson's disease. J Parkinsons Dis 9: 17-29.

BLESA J, TRIGO-DAMAS I, QUIROGA-VAREL AA, JACKSON-LEWIS VR. 2015. Oxidative stress and Parkinson's disease. Front Neuroanat 9: 91.

BOVÉ J, SERRATS J, MENGOD G, CORTÉS R, TOLOSA E \& MARIN C. 2005. Neuroprotection induced by the adenosine $A 2 A$ antagonist CSC in the 6-OHDA rat model of parkinsonism: Effect on the activity of striatal output pathways. Exp Brain Res 165(3): 362-374.

CAULI O, PINNA A, VALENTINI V \& MORELLI M. 2003. Subchronic caffeine exposure induces sensitization to caffeine and cross-sensitization to amphetamine ipsilateral turning behavior independent from dopamine release. Neuropsychopharmacology 28: 1752-1759.

CHEN JF \& CHERN Y. 2011. Impacts of methylxanthines and adenosine receptors on neurodegeneration: Human 
and experimental studies. Handb Exp Pharmacol 200: 267-310.

CHEN JF \& CUNHA RA. 2020. The belated US FDA approval of the adenosine A2A receptor antagonist istradefylline for treatment of Parkinson's disease. Purinergic Signal 16(2): 167-174.

CHEN JF, XU K, PETZER JP, STAAL R, XU YH, BEILSTEIN M, SONSALLA PK, CASTAGNOLI K, CASTAGNOLI N \& SCHWARZSCHILD MA. 2001. Neuroprotection by caffeine and $A(2 A)$ adenosine receptor inactivation in a model of Parkinson's disease. J Neurosci 21: 2-7.

CHO ES, JANG YJ, HWANG MK, KANG NJ, LEE KW \& LEE HJ. 2009. Attenuation of oxidative neuronal cell death by coffee phenolic phytochemicals. Mutat Res - Fundam Mol Mech Mutagen 661: 18-24.

CHU YF, BROWN PH, LYLE BJ, CHEN Y, RICHARD BM, WILLIAMS CE, LIN YC, HSU CW \& CHENG IH. 2009. Roasted coffees high in lipophilic antioxidants and chlorogenic acid lactones are more neuroprotective than green coffees. I Agric Food Chem 57: 9801-9808.

COSTA J, LUNET N, SANTOS C, SANTOS I \& VAZ-CARNEIRO A. 2010. Caffeine exposure and the risk of Parkinson's disease: $A$ systematic review and meta-analysis of observational studiess. J Alzheimer's Dis 20(Suppl 1): S221-S238.

CROPLEY V, CROFT R, SILBER B, NEALE C, SCHOLEY A, STOUGH C \& SCHMITT J. 2012. Does coffee enriched with chlorogenic acids improve mood and cognition after acute administration in healthy elderly? A pilot study. Psychopharmacology (Berl) 219: 737-749.

DA CUNHA C, WIETZIKOSKI EC, FERRO MM, MARTINEZ GR, VITAL MABF, HIPÓLIDE D, TUFIK S \& CANTERAS NS. 2008. Hemiparkinsonian rats rotate toward the side with the weaker dopaminergic neurotransmission. Behav Brain Res 189: 364-372.

DAGLIA M, PAPETTI A, GREGOTTI C, BERTĖ F \& GAZZANI G. 2000. In vitro antioxidant and ex vivo protective activities of green and roasted coffee. J Agric Food Chem 48: 1449-1454.

DEL REY NLG, QUIROGA-VARELA A, GARBAYO E, CARBALLOCARBAJAL I, FERNÁNDEZ-SANTIAGO R, MONJE MHG, TRIGODAMAS I, BLANCO-PRIETO MJ \& BLESA J. 2018. Advances in parkinson's disease: 200 years later. Front Neuroanat 12: 1-14.

DEUMENS R, BLOKLAND A \& PRICKAERTS J. 2002. Modeling Parkinson's disease in rats: An evaluation of 6-OHDA lesions of the nigrostriatal pathway. Exp Neurol 175: 303-317.
DI MATTEO $\vee$ \& ESPOSITO E. 2003. Biochemical and therapeutic effects of antioxidants in the treatment of Alzheimer's disease, Parkinson's disease, and amyotrophic lateral sclerosis. Curr Drug Targets CNS Neurol Disord 2: 95-107.

GÓNGORA-ALFARO JL, MOO-PUC RE, VILLANUEVA-TOLEDO JR, ALVAREZ-CERVERA FJ, BATA-GARCÍA JL, HEREDIA-LÓPEZ FJ \& PINEDA JC. 2009. Long-lasting resistance to haloperidolinduced catalepsy in male rats chronically treated with caffeine. Neurosci Lett 463: 210-214.

HEČIMOVIĆ I, BELŠČAK-CVITANOVIĆ A, HORŽIĆ D \& KOMES D. 2011. Comparative study of polyphenols and caffeine in different coffee varieties affected by the degree of roasting. Food Chem 129: 991-1000.

HEITMAN E \& INGRAM DK. 2017. Cognitive and neuroprotective effects of chlorogenic acid. Nutr Neurosci 20: 32-39.

HU G, BIDEL S, JOUSILAHTI P, ANTIKAINEN R \& TUOMILEHTO J. 2007. Coffee and tea consumption and the risk of Parkinson's disease. Mov Disord 22: 2242-2248.

IANCU R, MOHAPEL P, BRUNDIN P \& PAUL G. 2005. Behavioral characterization of a unilateral 6-OHDA-lesion model of Parkinson's disease in mice. Behav Brain Res 162: 1-10.

JEON JS, KIM HT, JEONG IH, HONG SR, OH MS, YOON MH, SHIM JH, JEONG JH \& ABD EL-ATY AM. 2019. Contents of chlorogenic acids and caffeine in various coffee-related products. J Adv Res 17: 85-94.

KACHROO A, IRIZARRY MC \& SCHWARZSCHILD MA. 2010. Caffeine protects against combined paraquat and maneb-induced dopaminergic neuron degeneration. Exp Neurol 223: 657-661.

KACZYŃSKA K \& ANDRZEJEWSKI K. 2020. 6-hydroxydopamineinduced model of Parkinson's disease. 1st ed., In: Colin R. Martin, Victor R. Preedy (editors) Genetics, Neurology, $1612 \mathrm{p}$.

KALDA A, YU L, OZTAS E \& CHEN JF. 2006. Novel neuroprotection by caffeine and adenosine $\mathrm{A} 2 \mathrm{~A}$ receptor antagonists in animal models of Parkinson's disease. J Neurol Sci 24: 9-15.

KELSEY JE, LANGELIER NA, ORIEL BS \& REEDY C. 2009. The effects of systemic, intrastriatal, and intrapallidal injections of caffeine and systemic injections of A2A and $\mathrm{A} 1$ antagonists on forepaw stepping in the unilateral 6-OHDA-lesioned rat. Psychopharmacology (Berl) 201: 529-539.

LANE EL, CHEETHAM SC \& JENNER P. 2006. Does contraversive circling in the 6-OHDA-lesioned rat indicate an ability to induce motor complications as well as therapeutic effects in Parkinson's disease? Exp Neurol 197: 284-290. 
LEE KW, IM JY, WOO JM, GROSSO H, KIM YS, CRISTOVAO AC, SONSALLA PK, SCHUSTER DS, JALBUT MM, FERNANDEZ JR, VORONKOV M, JUNN E, BRAITHWAITE SP, STOCK JB \& MOURADIAN MM. 2013. Neuroprotective and Anti-inflammatory Properties of a Coffee Component in the MPTP Model of Parkinson's Disease. Neurotherapeutics 10: 143-153.

LEE M, MCGEER EG \& MCGEER PL. 2016. Quercetin, not caffeine, is a major neuroprotective component in coffee. Neurobiol Aging 46: 113-123.

LUAN Y, REN X, ZHENG W, ZENG Z, GUO Y, HOU Z, GUO W, CHEN X, LI F \& CHEN JF. 2018. Chronic caffeine treatment protects against $\alpha$-synucleinopathy by reestablishing autophagy activity in the mouse striatum. Front Neurosci 12: 301.

MACHADO-FILHO JA, CORREIA AO, MONTENEGRO ABA, NOBRE MEP, CERQUEIRA GS, NEVES KRT, NAFFAH-MAZZACORATTI M DA G, CAVALHEIRO EA, DE CASTRO BRITO GA \& DE BARROS VIANA GS. 2014. Caffeine neuroprotective effects on 6-OHDAlesioned rats are mediated by several factors, including pro-inflammatory cytokines and histone deacetylase inhibitions. Behav Brain Res 264: 116-125.

MACHADO RB, TUFIK S \& SUCHECKI D. 2008. Chronic stresS during paradoxical sleep deprivation increases paradoxical sleep rebound: Association with prolactin plasma levels and brain serotonin content. Psychoneuroendocrinology 33: 1211-1224.

MACHEINER L, SCHMIDT A, SCHREINER M \& MAYER HK. 2019. Green coffee infusion as a source of caffeine and chlorogenic acid. J Food Compos Anal 84: 103307.

MAITI P, MANNA J, DUNBAR GL, MAITI P \& DUNBAR GL. 2017. Current understanding of the molecular mechanisms in Parkinson's disease: Targets for potential treatments. Transl Neurodegener 6: 1-35.

MALEC D. 1997. Haloperidol-induced catalepsy is influenced by adenosine receptor antagonists. Pol J Pharmacol 49: 323-327.

MANCINI RS, WANG Y \& WEAVER DF. 2018. Phenylindanes in brewed coffee inhibit amyloid-beta and tau aggregation. Front Neurosci 12: 735.

MIYAZAKI I, ISOOKAN, WADAK, KIKUOKAR, KITAMURAY \&ASANUMA M. 2019. Effects of enteric environmental modification by coffee components on neurodegeneration in rotenonetreated mice. Cells 8: 221.

MONTEIRO MC \& FARAH A. 2012. Chlorogenic acids in Brazilian Coffea arabica cultivars from various consecutive crops. Food Chem 134: 611-614.

MOO-PUC RE, GÓNGORA-ALFARO JL, ALVAREZ-CERVERA FJ, PINEDA JC, ARANKOWSKY-SANDOVAL G \& HEREDIA-LÓPEZ F. 2003. Caffeine and muscarinic antagonists act in synergy to inhibit haloperidol-induced catalepsy. Neuropharmacology 45: 493-503.

NABAVI SF, TEJADA S, SETZER WN, GORTZI O, SUREDA A, BRAIDY N, DAGLIA M, MANAYI A \& NABAVI SM. 2016. Chlorogenic acid and mental diseases: from chemistry to medicine. Curr Neuropharmacol 15: 471-479.

NAVARRA G, MOSCHETTI M, GUARRASI V, MANGIONE MR \& MILITELLO V, LEONE M. 2017. Simultaneous determination of caffeine and chlorogenic acids in green coffee by UV/ Vis spectroscopy. J Chem 2017: Article ID 6435086.

OCHIAI R, SAITOU K, SUZUKAMO C, OSAKI N \& ASADA T. 2019. Effect of chlorogenic acids on cognitive function in mild cognitive impairment: a randomized controlled crossover trial. J Alzheimers Dis 72: 1209-1216.

PANUSA A, PETRUCCI R, LAVECCHIA R \& ZUORRO A. 2017. UHPLCPDA-ESI-TOF/MS metabolic profiling and antioxidant capacity of arabica and robusta coffee silverskin: Antioxidants vs phytotoxins. Food Res Int 99: 155-165.

PAXINOS G \& WATSON C. 2004. The Rat Brain in Stereotaxic Coordinates, 5th ed., Journal of Chemical Information and Modeling, 209 p.

POHL F \& LIN PKT. 2018. The potential use of plant natural products and plant extracts with antioxidant properties for the prevention/treatment of neurodegenerative diseases: In vitro, in vivo and clinical trials. Molecules 23: 3283.

PRIFTIS A, STAGOS D, KONSTANTINOPOULOS K, TSITSIMPIKOU C, SPANDIDOS DA, TSATSAKIS AM, TZATZARAKIS MN \& KOURETAS D. 2015. Comparison of antioxidant activity between green and roasted coffee beans using molecular methods. Mol Med Rep 12: 7293-7302.

QI H \& LI S. 2014. Dose-response meta-analysis on coffee, tea and caffeine consumption with risk of Parkinson's disease. Geriatr Gerontol Int 14: 430-439.

RODRIGUES E, GIANFRATTI B, TABACH R, NEGRI G \& MENDES FR. 2008. Preliminary investigation of the central nervous system effects of "Tira-capeta" (Removing the Devil), a cigarette used by some Quilombolas living in pantanal wetlands of Brazil. Phyther Res 22: 1248-1255.

ROSS GW, ABBOTT RD, PETROVITCH H, MORENS DM, GRANDINETTI A, TUNG KH, TANNER CM, MASAK KH, BLANCHETTE PL, CURB JD, POPPER JS \& WHITE LR. 2000. Association of coffee and caffeine intake with the risk of Parkinson disease. J Am Med Assoc 283: 2674-2679.

SÄÄKSJÄRVI K, KNEKT P, RISSANEN H, LAAKSONEN MA, REUNANEN A \& MÄNNISTÖ S. 2008. Prospective study of coffee consumption and risk of Parkinson's disease. Eur J Clin Nutr 62: 908-915. 
SCHWARTING RKW \& HUSTON JP. 1996. Unilateral 6-hydroxydopamine lesions of meso-striatal dopamine neurons and their physiological sequelae. Prog Neurobiol 49: 215-266.

SHAN S, TIAN L \& FANG R. 2019. Chlorogenic acid exerts beneficial effects in 6-hydroxydopamine-induced neurotoxicity by inhibition of endoplasmic reticulum stress. Med Sci Monit 25: 453-459.

SINGH SS, RAI SN, BIRLA H, ZAHRA W, KUMAR G, GEDDA MR, TIWARI N, PATNAIK R, SINGH RK \& SINGH SP. 2018. Effect of chlorogenic acid supplementation in MPTP-intoxicated mouse. Front Pharmacol 9: 757.

SOCAŁA K, SZOPA A, SEREFKO A, POLESZAK E \& WLAŹ P. 2020. Neuroprotective effects of coffee bioactive compounds: a review. Int J Mol Sci 22: 107.

STOCKS J, GUTTERIDGE JMC, SHARP RJ \& DORMANDY TL. 1974. Assay using brain homogenate for measuring the antioxidant activity of biological fluids. Clin Sci Mol Med 47: 215-222.

TAJIK N, TAJIK M, MACK I \& ENCK P. 2017. The potential effects of chlorogenic acid, the main phenolic components in coffee, on health: a comprehensive review of the literature. Eur J Nut 56: 2215-2244.

TARAM F, WINTER AN \& LINSEMAN DA. 2016. Neuroprotection comparison of chlorogenic acid and its metabolites against mechanistically distinct cell death-inducing agents in cultured cerebellar granule neurons. Brain Res 1648: 69-80.

TERAOKA M, NAKASO K, KUSUMOTO C, KATANO S, TAJIMA N, YAMASHITA A, ZUSHI T, ITO S \& MATSURA T. 2012. Cytoprotective effect of chlorogenic acid against $\alpha$-synuclein-related toxicity in catecholaminergic PC12 cells. J Clin Biochem Nutr 51: 122-127.

TÓTH A, ANTAL Z, BERECZKI D \& SPERLÁGH B. 2019. Purinergic Signalling in Parkinson's Disease: A Multi-target System to Combat Neurodegeneration. Neurochem Res 44: 2413-2422.

TREVITT J, VALLANCE C, HARRIS A \& GOODE T. 2009. Adenosine antagonists reverse the cataleptic effects of haloperidol: Implications for the treatment of Parkinson's disease. Pharmacol. Biochem Behav 92: 521-527.

TSAI SJ, CHAO CY \& YIN MC. 2011. Preventive and therapeutic effects of caffeic acid against inflammatory injury in striatum of MPTP-treated mice. Eur J Pharmacol 670: 441-447.

UNGERSTEDT U \& ARBUTHNOTT GW. 1970. Quantitative recording of rotational behavior in rats after 6-hydroxy-dopamine lesions of the nigrostriatal dopamine system. Brain Res 24: 485-493.

VAN DAM RM, HU FB \& WILLETT WC. 2020. Coffee, Caffeine, and Health. N Engl J Med 383: 369-378.

WOLSKA J, JANDA K, JAKUBCZYK K, SZYMKOWIAK M, CHLUBEK D \& GUTOWSKA I. 2017. Levels of Antioxidant Activity and Fluoride Content in Coffee Infusions of Arabica, Robusta and Green Coffee Beans in According to their Brewing Methods. Biol Trace Elem Res 179: 327-333.

XU K, XU YH, CHEN JF \& SCHWARZSCHILD MA. 2010. Neuroprotection by caffeine: Time course and role of its metabolites in the MPTP model of Parkinson's disease. Neuroscience 167: 475-481.

YAN R, ZHANG J, PARK HJ, PARK ES, OH S, ZHENG H, JUNN E, VORONKOV M, STOCK JB \& MOURADIAN MM. 2018. Synergistic neuroprotection by coffee components eicosanoyl5-hydroxytryptamide and caffeine in models of Parkinson's disease and DLB. Proc Natl Acad Sci USA 115: E12053-E12062.

YUAN H, SARRE S, EBINGER G \& MICHOTTE Y. 2005. Histological, behavioural and neurochemical evaluation of medial forebrain bundle and striatal 6-OHDA lesions as rat models of Parkinson's disease. J Neurosci Methods 144: 35-45.

ZHOU XD, XIE SP, SAW WT, HO P, WANG H, LEI Z, YI Z \& TAN EK. 2019. The Therapeutic Implications of Tea Polyphenols Against Dopamine (DA) Neuron Degeneration in Parkinson's Disease (PD). Cells 8: 911.

\section{SUPPLEMENTARY MATERIAL}

\section{Figure S1.}

\section{Abbreviations}

5-HIAA, 5-hydroxyindolacetic acid; 5-HT, serotonin; 6-OHDA, 6-hydroxydopamine; CAF, caffeine; CE, Coffeea arabica; DA, dopamine; DOPAC, dihydroxyphenylacetic acid; HPLC/DAD, high-performance liquid chromatography with Diodo Array detector; HVA, homovanillic acid; MFB, medial forebrain bundle; MPTP, 1-methyl4-phenyl-1,2,3,6-tetrahydropyridine; NE, noradrenaline; PD, Parkinson's disease

Paxinos coordinates: AP, anteroposterior; ML, mediolateral; DV, dorsoventral; 
Administration routes: ip, intraperitoneally; po, per oral; sc, subcutaneously

\section{How to cite}

MOLSKA GR, PAULA-FREIRE LIG, SAKALEM ME, KÖHN DO, NEGRI G, CARLINI EA \& MENDES FR. 2021. Green coffee extract attenuates Parkinson'srelated behaviors in animal models. An Acad Bras Cienc 93: e20210481. DOI 10.1590/0001-3765202120210481.

Manuscript received on April 1, 2021;

accepted for publication on July 1, 2021

GRAZIELLA R. MOLSKA ${ }^{1,4}$

https://orcid.org/0000-0003-1612-6903

LYVIA IZAURA G. PAULA-FREIRE ${ }^{1}$

https://orcid.org/0000-0002-2063-7346

MARNA E. SAKALEM ${ }^{1}$

https://orcid.org/0000-0002-3143-4093

DANIELE O. KÖHN ${ }^{1}$

https://orcid.org/0000-0002-7099-5432

\section{GIUSEPPINA NEGRI ${ }^{1}$}

https://orcid.org/0000-0002-4858-6632

\section{ELISALDO A. CARLINI}

https://orcid.org/0000-0002-9181-6659

(In memoriam)

\section{FÚLVIO R. MENDES 3}

https://orcid.org/0000-0002-8706-1361
'Universidade Federal de São Paulo, Departamento de Psicobiologia, Rua Botucatu, 862, 10 andar, ECB, 04023-062 São Paulo, SP, Brazil

${ }^{2}$ Universidade Federal de São Paulo, Departamento de Medicina Preventiva, Rua Botucatu, 740, 4응 andar, 04024-002 São Paulo, SP, Brazil

${ }^{3}$ Universidade Federal do ABC, Centro de Ciências Naturais e Humanas, Rua Arcturus, 03, 09606070 São Bernardo do Campo, SP, Brazil

${ }^{4}$ Faculty of Dentistry, University of Toronto, 124 Edward St, Toronto, Ontario, M5G 1G6, Canada

Correspondence to: Fúlvio Rieli Mendes

E-mails: fulvio.mendes@ufabc.edu.br,fulviorm@hotmail.com

\section{Author contributions}

GRM, LIGPF, and MES contributed to the acquisition, analysis and interpretation of data, draft and revising the manuscript. DOK contributed to English translation and draft and revising the manuscript. GN contributed to the caffeine quantification, analysis and interpretation of data, draft and revising the manuscript. EAC and FRM contributed to the conception and design, analysis an interpretation of data, draft and revising the manuscript. The authors declare that all data were generated in-house and that no paper mill was used. All authors reviewed and approved the content of the manuscript.

(cc) BY 